\title{
Application of a multivariable feedback linearization scheme for STATCOM control
}

\author{
N.C. Sahoo ${ }^{\mathrm{a}}$, B.K. Panigrahi ${ }^{\mathrm{a}}$, P.K. Dash ${ }^{\mathrm{b}}$, G. Panda ${ }^{\mathrm{c}, *}$ \\ ${ }^{a}$ Department of Electrical Engineering, Regional Engineering College, Rourkela 769 008, India \\ ${ }^{\mathrm{b}}$ Faculty of Engineering, Multimedia University, Malaysia \\ ${ }^{\mathrm{c}}$ Department of Applied Electronics and Instrumentation Engineering, Regional Engineering College, Rourkela 769008 , India
}

\begin{abstract}
This paper investigates application of a multivariable control technique to the multi-input multi-output (MIMO) nonlinear model of a static synchronous compensator (STATCOM). The proposed controller design is based on a feedback linearization scheme. Its prime goal is the coordinated control of ac and dc voltage for a STATCOM installed in a power distribution system. First, the nonlinear mathematical model of STATCOM along with the distribution system is derived. Then, by using input-output feedback linearization, a state feedback control law is obtained by pole placement. The efficacy of the control strategy is evaluated by digital computer simulations on the complete system for various types of loads and/or disturbances. The comparative study of these results with those obtained in a conventional cascade control architecture establishes the elegance of this new control scheme.
\end{abstract}

Keywords: Static synchronous compensator; Distribution system; Feedback linearization; Nonlinear control

\section{Introduction}

Because of the sophisticated development in power electronics technology, the static synchronous compensator (STATCOM) is assuming a significant role in reactive power modulation in modern electric power networks. There are several successful applications of STATCOM for reactive power supply [1], load balancing [2] as well as rapid voltage control [3,4]. The first full-scale STATCOM has become operational since 1991 [5].

The fundamental principle of a STATCOM installed in a power system is the generation of a controllable ac voltage source by a voltage source inverter (VSI) connected to a dc capacitor (energy storage device). The ac voltage source, in general, appears behind a transformer leakage reactance. The active and reactive power transfer between the power system and the STATCOM is caused by the voltage difference across this reactance. The ac voltage control is achieved by firing angle control. Ideally the output voltage of the VSI is in phase with the bus (where the STATCOM is connected) voltage. In steady state, the dc side capacitance is maintained at a fixed voltage and there is no real power exchange, except for losses.

The STATCOM differs from other reactive power generating devices (such as Capacitors, Static Var Compensators etc.) in the sense that the ability for energy storage is not a rigid necessity but is only required for system unbalance or harmonic absorption. As a consequence, the not-a-so-strict requirement for large energy storage device makes STATCOM more robust and it also enhances the response speed.

Basically, there are two control objectives implemented in the STATCOM. One is the ac voltage regulation of the power system at the bus where the STATCOM is connected and the other is dc voltage control across the capacitor inside the STATCOM. It is widely known that shunt reactive power injection can be used to control the bus voltage. In conventional control scheme, there are two voltage regulators designed for these purposes: ac voltage regulator for bus voltage control and dc voltage regulator for capacitor voltage control. In the simplest 
strategy, both the voltage regulators are proportionalintegral (PI) type cascaded controllers [6,7]. The modeling and control design is usually carried out in the synchronous $d-q$ frame, as it is quite standard [8]. Thus, the shunt current is split into $d$-axis and $q$-axis components. The reference values for these currents are obtained by separate PI regulators from dc voltage and ac-bus voltage errors, respectively. Then, subsequently, these reference currents are regulated by another set of PI regulators whose outputs are the $d$ axis and $q$-axis control voltages for the STATCOM. Although, this cascade control structure yields good performance, it is not very much effective for all operating conditions because, in general, one chosen set of PI-gains may not be suitable for all operating points. Moreover, it really becomes a hard task to choose the PI gains for the four PI regulators occurring in the cascade structure because of the inherent coupling between the $d$-axis and $q$-axis variables. Recently, a linear multivariable controller approach [9] has been used for the control design for better performance. However, since the complete model is highly nonlinear, the linear approach obviously does not lead to better dynamic decoupling.

This paper focuses on a nonlinear multivariable control technique for STATCOM using feedback linearization approach [10]. The feedback linearization technique is based on the idea of canceling the nonlinearities of the system and imposing a desired linear dynamics to control the system. There are reports of several successful applications of this control design [11-17]. The design procedure of feedback linearization is similar, in principle, to the inverse system method (ISM) [18], where inverse model of the plant is identified by some nonlinear identification tools. The artificial neural networks (ANN) can be employed for this purpose [19]. Here, a multivariable feedback linearizing controller is designed for the STATCOM, which is a MIMO system, installed in a distribution system. The control design has been tested by computer simulations under various types of disturbances and load (static as well as dynamic) changes. The comparison of these results with those obtained from conventional cascaded control structure reveals the supremacy of the proposed control design.

The remainder of the paper is organized as follows. Section 2 describes the modeling and the conventional cascade control scheme for a STATCOM connected in a distribution system. The design of the proposed control algorithm is detailed in Section 3. The computer simulation results are presented and discussed in Section 4. Finally Section 5 concludes this paper. The various parameters of the system and controllers are listed in Appendix A.

\section{Modeling and the cascade control scheme of STATCOM}

Fig. 1 shows the basic structure of a six-pulse STATCOM to a load bus in a power system where $R_{\mathrm{p}}$ represents the 'ON' state resistance of the switches including transformer leakage resistance, $L_{\mathrm{p}}$ is transformer leakage inductance and the switching losses are taken into account by a shunt dc-side resistance $R_{\mathrm{dc}}$. A VSI resides at the core of the STATCOM. It generates a balanced and controlled three-phase voltage $\mathbf{V}_{\mathrm{p}}$. The voltage control is achieved by firing angle control of the VSI. Under steady state, the dc-side capacitor possesses fixed voltage $V_{\mathrm{dc}}$ and there is no real power transfer, except for losses. Thus, the ac-bus voltage remains in phase with the fundamental component of $\mathbf{V}_{\mathrm{p}}$. However, the reactive power supplied by STATCOM is either inductive or capacitive depending upon the relative magnitude of fundamental component of $\mathbf{V}_{\mathrm{p}}$ with respect to $\mathbf{V}_{\mathrm{t}}$. If $\left|\mathbf{V}_{\mathrm{t}}\right|>\left|\mathbf{V}_{\mathrm{p}}\right|$ the VSI draws reactive power from the ac-bus whereas if $\left|\mathbf{V}_{\mathrm{t}}\right|<\left|\mathbf{V}_{\mathrm{p}}\right|$, it supplies reactive power to the ac-system.

\subsection{Modeling of the STATCOM}

This paper focuses on the STATCOM control in a distribution system (shown in Fig. 2). The sending end source is assumed to be a strong system with high short

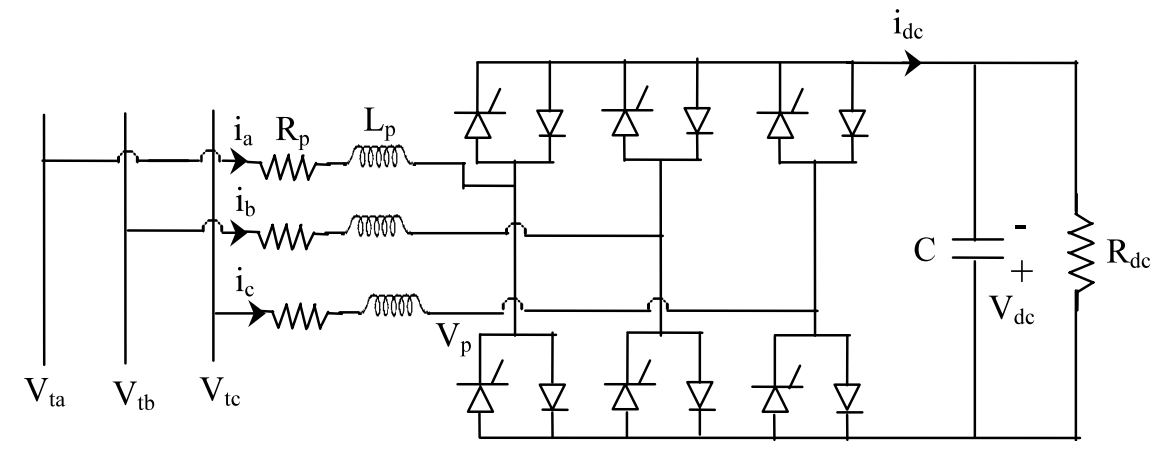

Fig. 1. Basic STATCOM connected to a load bus in power system. 


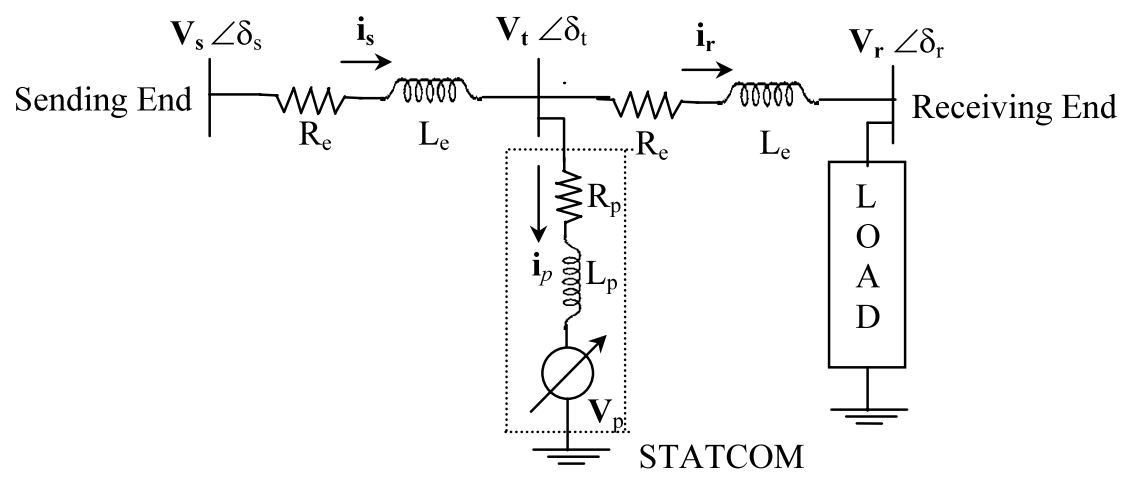

Fig. 2. Equivalent circuit of STATCOM connected in a distribution system.

circuit ratio and low impedance. Thus, the source voltage is treated as a constant source irrespective of variations in load current. The dynamic equations governing the instantaneous values of the three-phase voltages across the two sides of STATCOM and the current flowing into it are given by:

$$
\left(R_{\mathrm{p}}+L_{\mathrm{p}} \frac{\mathrm{d}}{\mathrm{d} t}\right) \mathbf{i}_{\mathrm{p}}=\mathbf{V}_{\mathrm{t}}-\mathbf{V}_{\mathrm{p}}
$$

where

$\mathbf{i}_{\mathrm{p}}=\left[\begin{array}{lll}i_{a} & i_{b} & i_{c}\end{array}\right]^{\mathrm{T}}$,

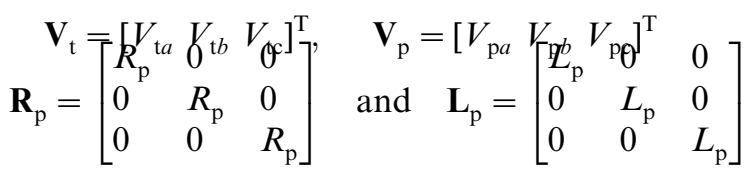

Under the assumption that the system has no zero sequence components, all currents and voltages can be uniquely represented by equivalent space phasors [20] and then transformed into the synchronous $d-q-o$ frame by applying the following Park's transformation ( $\theta$ is the angle between the $d$-axis and reference phase axis).

$$
\mathbf{T}=\frac{2}{3}\left[\begin{array}{lll}
\cos \theta & \cos \left(\theta-\frac{2 \pi}{3}\right) & \cos \left(\theta+\frac{2 \pi}{3}\right) \\
-\sin \theta & -\sin \left(\theta-\frac{2 \pi}{3}\right) & -\sin \left(\theta+\frac{2 \pi}{3}\right) \\
\frac{1}{\sqrt{2}} & \frac{1}{\sqrt{2}} & \frac{1}{\sqrt{2}}
\end{array}\right]
$$

Thus

$$
\left[\begin{array}{l}
V_{d} \\
V_{q} \\
V_{o}
\end{array}\right]=\mathbf{T}\left[\begin{array}{l}
V_{a} \\
V_{b} \\
V_{c}
\end{array}\right]
$$

and

$$
\left[\begin{array}{l}
i_{d} \\
i_{q} \\
i_{o}
\end{array}\right]=\mathbf{T}\left[\begin{array}{l}
i_{a} \\
i_{b} \\
i_{c}
\end{array}\right]
$$

Thus, the transformed dynamic equations are $\frac{\mathrm{d} i_{\mathrm{p} d}}{\mathrm{~d} t}=-\frac{R_{\mathrm{p}}}{L_{\mathrm{p}}} i_{\mathrm{p} d}+\omega i_{\mathrm{p} q}+\frac{1}{L_{\mathrm{p}}}\left(V_{\mathrm{t} d}-V_{\mathrm{p} d}\right)$

$\frac{\mathrm{d} i_{\mathrm{p} q}}{\mathrm{~d} t}=-\omega i_{\mathrm{p} d}-\frac{R_{\mathrm{p}}}{L_{\mathrm{p}}} i_{\mathrm{p} q}+\frac{1}{L_{\mathrm{p}}}\left(V_{\mathrm{t} q}-V_{\mathrm{p} q}\right)$

$\omega(=\mathrm{d} \theta / \mathrm{d} t)$ is the angular frequency of the source voltage.

It is to be noted that in the $d$ - and $q$-axis components of the VSI voltage, i.e. $V_{\mathrm{p} d}$ and $V_{\mathrm{p} q}$, all harmonics which are near to/above the VSI switching frequency are neglected. In the real-time implementation of these quantities, they should be converted into modulation index $(m)$ and phase angle $(\phi)$ :

$m=\frac{\sqrt{V_{\mathrm{p} d}^{2}+V_{\mathrm{p} q}^{2}}}{k V_{\mathrm{dc}}}$ and $\phi=\tan ^{-1}\left(\frac{V_{\mathrm{p} q}}{V_{\mathrm{p} d}}\right)$

where ' $k$ ' is a constant whose amplitude depends upon the adopted modulation technique.

For an effective dc-voltage control, the input power should be equal to the sum of load power (if any) and the charging rate of capacitor voltage on an instantaneous basis. Thus, by power balance between the ac input and the de output,

$$
\begin{aligned}
p & =\frac{3}{2}\left[V_{\mathrm{t} d} i_{\mathrm{p} d}+V_{\mathrm{t} q} i_{\mathrm{p} q}-\left(i_{\mathrm{p} d}^{2}+i_{\mathrm{p} q}^{2}\right) R_{\mathrm{p}}\right] \\
& =C V_{\mathrm{dc}} \frac{\mathrm{d} V_{\mathrm{dc}}}{\mathrm{d} t}+\frac{V_{\mathrm{dc}}^{2}}{R_{\mathrm{dc}}}
\end{aligned}
$$

Hence,

$\frac{\mathrm{d} V_{\mathrm{dc}}}{\mathrm{d} t}=\frac{3}{2} \frac{V_{\mathrm{t} d} i_{\mathrm{p} d}+V_{\mathrm{t} q} i_{\mathrm{p} q}-\left(i_{\mathrm{p} d}^{2}+i_{\mathrm{p} q}^{2}\right) R_{\mathrm{p}}}{C V_{\mathrm{dc}}}-\frac{V_{\mathrm{dc}}}{C R_{\mathrm{dc}}}$

Eq. (9) models the dynamic behavior of the dc-side capacitor voltage. In essence Eqs. (5), (6) and (9) together describe the dynamic model of the STATCOM and is summarized below for readiness in Eq. (10). 


$$
\begin{aligned}
& \frac{\mathrm{d}}{\mathrm{d} t}\left[\begin{array}{l}
i_{\mathrm{p} d} \\
i_{\mathrm{p} q} \\
V_{\mathrm{dc}}
\end{array}\right] \\
& =\left[\begin{array}{l}
-\frac{R_{\mathrm{p}}}{L_{\mathrm{p}}} i_{\mathrm{p} d}+\omega i_{\mathrm{p} q} \\
-\frac{R_{\mathrm{p}}}{L_{\mathrm{p}}} i_{\mathrm{p} q}-\omega i_{\mathrm{p} d} \\
\frac{3}{2 C V_{\mathrm{dc}}}\left[V_{\mathrm{t} d} i_{\mathrm{p} d}+V_{\mathrm{t} q} i_{\mathrm{p} q}-\left(i_{\mathrm{p} d}^{2}+i_{\mathrm{p} q}^{2}\right) R_{\mathrm{p}}\right]-\frac{V_{\mathrm{dc}}}{C R_{\mathrm{dc}}}
\end{array}\right] \\
& +\left[\begin{array}{ll}
\frac{1}{L_{\mathrm{p}}} & 0 \\
0 & \frac{1}{L_{\mathrm{p}}} \\
0 & 0
\end{array}\right]\left[\begin{array}{l}
V_{\mathrm{t} d}-V_{\mathrm{p} d} \\
V_{\mathrm{t} q}-V_{\mathrm{p} q}
\end{array}\right]
\end{aligned}
$$

\subsection{Cascade control scheme for STATCOM}

The conventional control strategy for STATCOM is concerned with the control of ac-bus and dc-bus voltage on both sides of STATCOM. The dual control objectives are met by generating appropriate current reference (for $d$ - and $q$-axis) and, then, by regulating these currents in the STATCOM. PI controllers are conventionally employed for both the tasks while attempting to decouple the $d$ - and $q$-axis current regulators. In this study, the strategy adopted in Refs. [7,8] for shunt current control has been taken. The STATCOM current $\left(i_{\mathrm{p}}\right)$ is split into real (in phase with ac-bus voltage) and reactive components. The reference value for the real current is decided so that the capacitor voltage is regulated by power balance. The reference for reactive component is determined by ac-bus voltage regulator. As per the strategy, the original currents in $d-q$ frame $\left(i_{\mathrm{p} d}, i_{\mathrm{pq}}\right)$ are now transformed into another frame, $d^{\prime}-q^{\prime}$ frame, where $d^{\prime}$-axis coincides with the ac-bus voltage $\left(V_{\mathrm{t}}\right)$, as shown in Fig. 3.

Thus, in $d^{\prime}-q^{\prime}$ frame, the currents $i_{\mathrm{p} d^{\prime}}$ and $i_{\mathrm{p} q^{\prime}}$ represent the real and reactive currents and they are given by:

$$
i_{\mathrm{p} d^{\prime}}=i_{\mathrm{p} d} \cos \delta_{\mathrm{t}}+i_{\mathrm{p} q} \sin \delta_{\mathrm{t}}
$$

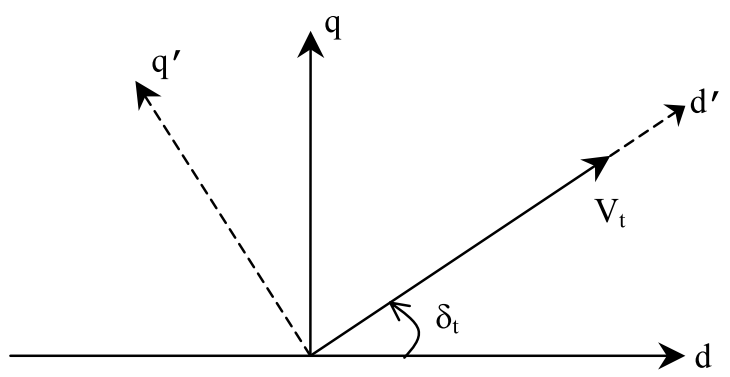

Fig. 3. Phasor diagram showing $d-q$ and $d^{\prime}-q^{\prime}$ frame. $i_{\mathrm{p} q^{\prime}}=i_{\mathrm{p} q} \cos \delta_{\mathrm{t}}-i_{\mathrm{p} d} \sin \delta_{\mathrm{t}}$

Now, for STATCOM current control, the same procedure as outlined in Ref. [8] has been adopted by reexpressing the differential equations (5) and (6) as:

$\frac{\mathrm{d} i_{\mathrm{p} d^{\prime}}}{\mathrm{d} t}=-\frac{R_{\mathrm{p}}}{L_{\mathrm{p}}} i_{\mathrm{p} d^{\prime}}+\omega i_{\mathrm{p} q^{\prime}}+\frac{1}{L_{\mathrm{p}}}\left(V_{\mathrm{t}}-V_{\mathrm{p} d^{\prime}}\right)$

$\frac{\mathrm{d} i_{\mathrm{p} q^{\prime}}}{\mathrm{d} t}=-\omega i_{\mathrm{p} d^{\prime}}-\frac{R_{\mathrm{p}}}{L_{\mathrm{p}}} i_{\mathrm{p} q^{\prime}}+\frac{1}{L_{\mathrm{p}}}\left(-V_{\mathrm{p} q^{\prime}}\right)$

where

$V_{\mathrm{p} d^{\prime}}=V_{\mathrm{p} d} \cos \delta_{\mathrm{t}}+V_{\mathrm{p} q} \sin \delta_{\mathrm{t}}$,

$V_{\mathrm{p} q^{\prime}}=V_{\mathrm{p} q} \cos \delta_{\mathrm{t}}-V_{\mathrm{p} d} \sin \delta_{\mathrm{t}}$,

and

$\omega=\omega_{0}+\frac{\mathrm{d} \delta_{\mathrm{t}}}{\mathrm{d} t}$

The VSI voltages are controlled as follows:

$$
\begin{aligned}
& V_{\mathrm{p} q^{\prime}}=-\left(\omega L_{\mathrm{p}} i_{\mathrm{p} d^{\prime}}+L_{\mathrm{p}} u_{q^{\prime}}\right) \\
& V_{\mathrm{p} d^{\prime}}=\omega L_{\mathrm{p}} i_{\mathrm{p} q^{\prime}}+V_{\mathrm{t}}-L_{\mathrm{p}} u_{d^{\prime}}
\end{aligned}
$$

By putting the above expressions for $V_{\mathrm{p} d^{\prime}}$ and $V_{\mathrm{p} q^{\prime}}$ in Eqs. (13) and (14), the following set of decoupled equations are obtained.

$\frac{\mathrm{d} i_{\mathrm{p} d^{\prime}}}{\mathrm{d} t}=-\frac{R_{\mathrm{p}}}{L_{\mathrm{p}}} i_{\mathrm{p} d^{\prime}}+u_{d^{\prime}}$

$\frac{\mathrm{d} i_{\mathrm{p} q^{\prime}}}{\mathrm{d} t}=-\frac{R_{\mathrm{p}}}{L_{\mathrm{p}}} i_{\mathrm{p} q^{\prime}}+u_{q^{\prime}}$

Also, the dc-bus voltage dynamic equation is now modified as:

$\frac{\mathrm{d} V_{\mathrm{dc}}}{\mathrm{d} t}=\frac{3}{2 C V_{\mathrm{dc}}}\left[V_{\mathrm{t}} i_{\mathrm{p} d^{\prime}}-\left(i_{\mathrm{p} d^{\prime}}^{2}+i_{\mathrm{p} q^{\prime}}^{2}\right) R_{\mathrm{p}}\right]-\frac{V_{\mathrm{dc}}}{C R_{\mathrm{dc}}}$

Now, the control signals $u_{d^{\prime}}$ and $u_{q^{\prime}}$ can be easily determined by linear PI controllers. The complete cascade control architecture is shown below in Fig. 4, where $K_{\mathrm{pt}}, K_{\mathrm{it}}, K_{\mathrm{pc}}, K_{\mathrm{ic}}, K_{\mathrm{p} q}, K_{\mathrm{i} q}, K_{\mathrm{p} d}$, and $K_{\mathrm{i} d}$ are the respective gains of the PI controllers.

In this study, the above design has been used for demonstration of STATCOM control. This approach leads to good control as illustrated by the simulation results shown in Section 4 of this paper. However, it must be emphasized here that the decoupling approach taken in the above is not able to decouple the $d-q$ currents completely because of the coupled equations (18) and (19) and, finally, in the frame transformation from $d^{\prime}-q^{\prime}$ to $d-q$. Moreover, there are several PI controller gains to be determined for an effective control on the complete system. This obviously demands a lot of trial and error approach. Further, the above decoupling 


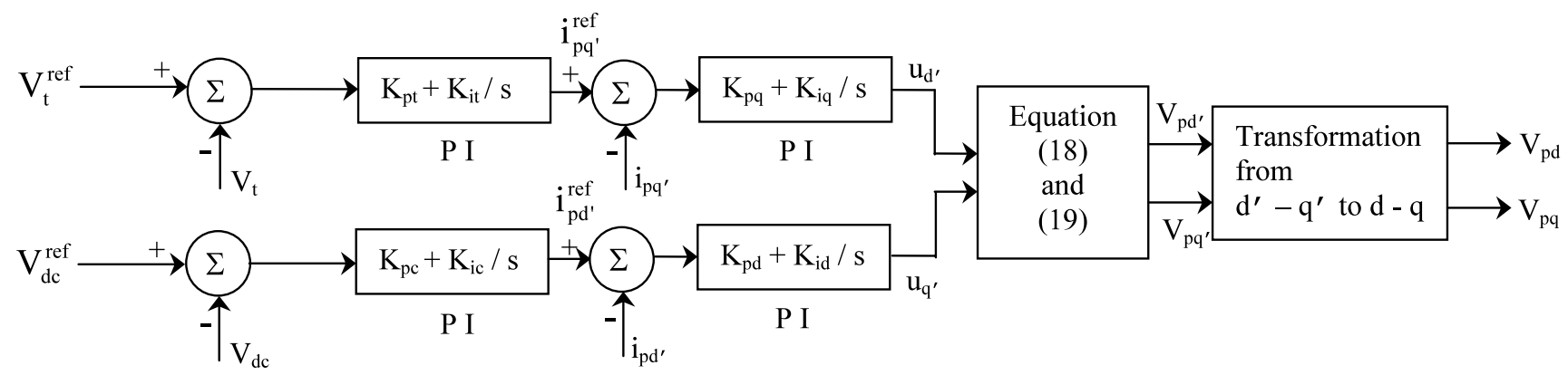

Fig. 4. Cascade control architecture for STATCOM control.

technique does not take into account the coupling resulting through the dc-capacitor voltage. All these difficulties always demand better and deeper modern control engineering approach. Such an approach using feedback linearization has been proposed in this study. This technique attempts to linearize the system by nonlinear transformation and the complete STATCOM system is viewed as a whole for the control design. The details of the design algorithm are described in the following section.

\section{Feedback linearizing control of STATCOM}

\subsection{Feedback linearizing control}

A brief review of nonlinear control using feedback linearization [10] is presented here. Without loss of generality, the following MIMO system is considered.

$\dot{\mathbf{x}}=\mathbf{f}(\mathbf{x})+\mathbf{g}(\mathbf{x}) \mathbf{u}$

$\mathbf{y}=\mathbf{h}(\mathbf{x})$

where $\mathbf{x}\left(\in \mathfrak{R}^{n}\right)$ is state vector, $\mathbf{u}\left(\in \mathfrak{R}^{m}\right)$ represents control inputs, $\mathbf{y}\left(\in \mathfrak{R}^{m}\right)$ stands for outputs, $\mathbf{f}$ and $\mathbf{g}$ are smooth vector fields, and $\mathbf{h}$ is a smooth scalar function. The input-output linearization of the above MIMO system is achieved by differentiating $y$ of the system until the inputs appear explicitly. Thus, by differentiating Eq. (24),

$\dot{y}_{i}=L_{f} h_{i}+\sum_{j=1}^{m}\left(L_{g j} h_{i}\right) u_{j}, \quad i=l, \ldots, m$

where $L_{f} h$ and $L_{g} h$ represent the Lie derivatives of $h(x)$ with respect to $f(x)$ and $g(x)$, respectively. The key point is that, if $L_{g j} L_{f}^{\left(r_{i}-1\right)} h_{i}(x)=0$ for all $j$, then the inputs do not appear in Eq. (25) and further differentiation is to be repeated as

$y_{i}^{\left(r_{i}\right)}=L_{f}^{\left(r_{i}\right)} h_{i}+\sum_{j=1}^{m}\left(L_{g j} L_{f}^{\left(r_{i}-1\right)} h_{i}\right) u_{j}, \quad i=l, \ldots, m$

such that $L_{g j} L_{f}^{\left(r_{i}-1\right)} h_{i}(x) \neq 0$ for at least one $j$. This procedure is repeated for each output $y_{i}$. Thus, there will be a set of $m$ equations given by

$$
\left[\begin{array}{l}
y_{1}^{\left(r_{1}\right)} \\
y_{m}^{\left(r_{m}\right)}
\end{array}\right]=\left[\begin{array}{l}
L_{f}^{r_{1}} h_{1}(x) \\
L_{f}^{r_{m}} h_{m}(x)
\end{array}\right]+\mathbf{E}(\mathbf{x})\left[\begin{array}{l}
u_{1} \\
u_{m}
\end{array}\right]
$$

where $\mathbf{E}(\mathbf{x})$ is expressed by:

$\mathbf{E}(\mathbf{x})=\left[\begin{array}{lllll}L_{g 1} L_{f}^{r_{1}-1} h_{1} \cdots & \cdots & L_{g m} L_{f}^{r_{1}-1} h_{1} \\ \cdots & \cdots & \cdots & \cdots & \\ \cdots & \cdots & \cdots & \cdots & \\ L_{g 1} L_{f}^{r_{m}-1} h_{m} & & L_{g m} & L_{f}^{r_{m}-1} h_{m}\end{array}\right]$

$\mathbf{E}(\mathbf{x})$ is suitably called as the decoupling matrix for the MIMO system. If $\mathbf{E}(\mathbf{x})$ is nonsingular, then the control $\mathbf{u}$ can be obtained as:

$\mathbf{u}=-\mathbf{E}^{-1}(\mathbf{x})\left[\begin{array}{l}L_{f}^{r_{1}} h_{1}(x) \\ \cdots \\ \cdots \\ L_{f}^{r_{m}} h_{m}(x)\end{array}\right]+\mathbf{E}^{-1}(x)\left[\begin{array}{l}v_{1} \\ \cdot \\ \cdot \\ v_{m}\end{array}\right]$

where $\left[v_{1} \cdots v_{m}\right]^{\mathrm{T}}$ are the new set of inputs defined by the designer. The resultant dynamics of the system with new control is easily obtained by substitution of Eq. (29) in Eq. (27) and is given by,

$\left[\begin{array}{l}y_{1}^{\left(r_{1}\right)} \\ \cdot \\ y_{m}^{\left(r_{m}\right)}\end{array}\right]=\left[\begin{array}{l}v_{1} \\ \cdot \\ v_{m}\end{array}\right]$

It is readily noticed that the input-output relation in Eq. (30) is decoupled and linear.

\subsection{Nonlinear control design for STATCOM}

As stated earlier, in the STATCOM control, there are two broad objectives, i.e. ac-bus voltage $\left(V_{\mathrm{t}}\right)$ and dc-bus voltage $\left(V_{\mathrm{dc}}\right)$ control. In the present control design, $V_{\mathrm{t}}$ is taken as an additional state in addition to the other three states $\left(i_{\mathrm{p} d^{\prime}}, i_{\mathrm{p} q^{\prime}}\right.$, and $\left.V_{\mathrm{dc}}\right)$ in the STATCOM modeling. The dynamic equation for $V_{\mathrm{t}}$ is obtained as follows with reference to Fig. 2 (in the $d^{\prime}-q^{\prime}$ frame).

$V_{\mathrm{t}}=V_{\mathrm{s} d^{\prime}}-R_{\mathrm{e}}\left(i_{\mathrm{p} d^{\prime}}+i_{\mathrm{r} d^{\prime}}\right)+\omega_{0} L_{\mathrm{e}}\left(i_{\mathrm{p} q^{\prime}}+i_{\mathrm{r} q^{\prime}}\right)$

Thus, with the earlier assumption of constant source voltage, 


$$
\begin{aligned}
\frac{\mathrm{d} V_{\mathrm{t}}}{\mathrm{d} t}= & {\left[\frac{R_{\mathrm{e}} R_{\mathrm{p}}}{L_{\mathrm{p}}}-\omega_{0}^{2} L_{\mathrm{e}}\right] i_{\mathrm{p} d^{\prime}}-\left[\omega_{0} R_{\mathrm{e}}+\frac{\omega_{0} R_{\mathrm{p}} L_{\mathrm{e}}}{L_{\mathrm{p}}}\right] i_{\mathrm{p} q^{\prime}} } \\
& -\frac{R_{\mathrm{e}}}{L_{\mathrm{p}}} V_{\mathrm{t}}-\frac{R_{\mathrm{e}}}{L_{\mathrm{p}}}\left(-V_{\mathrm{p} d^{\prime}}\right)+\frac{\omega_{0} L_{\mathrm{e}}}{L_{\mathrm{p}}}\left(-V_{\mathrm{p} q^{\prime}}\right)-R_{\mathrm{e}} \dot{i}_{\mathrm{r} d^{\prime}} \\
& +\omega_{0} L_{\mathrm{e}} \dot{i}_{\mathrm{r} q^{\prime}}
\end{aligned}
$$

Now, for the control design, the complete state space model is expressed in the form of Eqs. (23) and (24) as follows.

$\mathbf{x}=\left[\begin{array}{l}x_{1} \\ x_{2} \\ x_{3} \\ x_{4}\end{array}\right]=\left[\begin{array}{l}i_{\mathrm{p} d^{\prime}} \\ i_{\mathrm{p} q^{\prime}} \\ V_{\mathrm{dc}} \\ V_{\mathrm{t}}\end{array}\right], \quad \mathbf{u}=\left[\begin{array}{l}u_{1} \\ u_{2}\end{array}\right]=\left[\begin{array}{l}-V_{\mathrm{pd} d^{\prime}} \\ -V_{\mathrm{p} q^{\prime}}\end{array}\right]$

$\dot{x}_{1}=f_{1}(\mathbf{x})+g_{1} u_{1}$

$\dot{x}_{2}=f_{2}(\mathbf{x})+g_{2} u_{2}$

$\dot{x}_{3}=f_{3}(\mathbf{x})$

$\dot{x}_{4}=f_{4}(\mathbf{x})+g_{41} u_{1}+g_{42} u_{2}$

where

$f_{1}(\mathbf{x})=-\frac{R_{\mathrm{p}}}{L_{\mathrm{p}}} x_{1}+\omega x_{2}+\frac{1}{L_{\mathrm{p}}} x_{4}$

$g_{1}=\frac{1}{L_{\mathrm{p}}}=g_{2}$

$f_{2}(\mathbf{x})=-\omega x_{1}-\frac{R_{\mathrm{p}}}{L_{\mathrm{p}}} x_{2}$

$f_{3}(\mathbf{x})=\frac{3}{2 C x_{3}}\left[x_{1} x_{4}-R_{\mathrm{p}}\left(x_{1}^{2}+x_{2}^{2}\right)\right]-\frac{x_{3}}{C R_{\mathrm{dc}}}$

$f_{4}(\mathbf{x})=\left[\frac{R_{\mathrm{e}} R_{\mathrm{p}}}{L_{\mathrm{p}}}-\omega_{0}^{2} L_{\mathrm{e}}\right] x_{1}-\left[\omega_{0} R_{\mathrm{e}}+\frac{\omega_{0} R_{\mathrm{p}} L_{\mathrm{e}}}{L_{\mathrm{p}}}\right] x_{2}-\frac{R_{\mathrm{e}}}{L_{\mathrm{p}}} x_{4}$

$$
-R_{\mathrm{e}} \dot{i}_{r d^{\prime}}+\omega_{0} L_{\mathrm{e}} \dot{i}_{r q^{\prime}}
$$

$g_{41}=-\frac{R_{\mathrm{e}}}{L_{\mathrm{p}}}, \quad g_{42}=\frac{\omega_{0} L_{\mathrm{e}}}{L_{\mathrm{p}}}$

The outputs of the system are $V_{\mathrm{t}}$ and $V_{\mathrm{dc}}$.

Thus, $y_{1}=V_{\mathrm{t}}$ and $y_{2}=V_{\mathrm{dc}}$

Proceeding with the exact steps as outlined in the previous sub-section, the following can be obtained.

$$
\begin{aligned}
{\left[\begin{array}{l}
\dot{y}_{1} \\
\ddot{y}_{2}
\end{array}\right]=} & {\left[\begin{array}{l}
f_{4}(\mathbf{x}) \\
a_{11} f_{1}(\mathbf{x})+a_{12} f_{2}(\mathbf{x})+a_{13} f_{3}(\mathbf{x})+a_{14} f_{4}(\mathbf{x})
\end{array}\right] } \\
& +\left[\begin{array}{ll}
g_{41} & g_{42} \\
a_{11} g_{1}+a_{14} g_{41} & a_{12} g_{2}+a_{14} g_{42}
\end{array}\right]\left[\begin{array}{l}
u_{1} \\
u_{2}
\end{array}\right] \\
= & \mathbf{A}(\mathbf{x})+\mathbf{E}(\mathbf{x})\left[\begin{array}{l}
u_{1} \\
u_{2}
\end{array}\right]
\end{aligned}
$$

where

$$
\begin{aligned}
& a_{11}=\frac{3}{2 C x_{3}}\left(x_{4}-2 R_{\mathrm{p}} x_{1}\right) \\
& a_{12}=-\frac{3 R_{\mathrm{p}} x_{2}}{C x_{3}} \\
& a_{13}=\frac{3}{2 x_{3}^{2}}\left[R_{\mathrm{p}}\left(x_{1}^{2}+x_{2}^{2}\right)-x_{1} x_{4}\right]-\frac{1}{C R_{\mathrm{dc}}} \\
& a_{14}=\frac{3 x_{1}}{2 C x_{3}}
\end{aligned}
$$

Thus,

$\left[\begin{array}{l}u_{1} \\ u_{2}\end{array}\right]=\mathbf{E}^{-1}(\mathbf{x})\left[-\mathbf{A}(\mathbf{x})+\left[\begin{array}{l}v_{1} \\ v_{2}\end{array}\right]\right]$

For tracking of $V_{\mathrm{t}}$ and $V_{\mathrm{dc}}$, the new control inputs $v_{1}$ and $v_{2}$ are selected as (by both proportional and integral control):

$\left[\begin{array}{l}v_{1} \\ v_{2}\end{array}\right]=\left[\begin{array}{l}\dot{y}_{1 \mathrm{ref}}+K_{11} e_{1}+K_{12} \int e_{1} \mathrm{~d} t \\ \ddot{y}_{2 \mathrm{ref}}+K_{21} \dot{e}_{2}+K_{22} e_{2}+K_{23} \int e_{2} \mathrm{~d} t\end{array}\right]$

where $y_{1 \text { ref }}$ is the ac bus reference voltage ( $\left.V_{\mathrm{t}}^{\text {ref }}\right)$ and $y_{2 \text { ref }}$ is the dc bus reference voltage $\left(V_{\mathrm{dc}}^{\text {ref }}\right)$ and $e_{1}$ and $e_{2}$ are error variables defined by:

$e_{1}=V_{\mathrm{t}}^{\mathrm{ref}}-V_{\mathrm{t}}$ and $e_{2}=V_{\mathrm{dc}}^{\mathrm{ref}}-V_{\mathrm{dc}}$

From Eq. (52), the error dynamics are given by:

$\ddot{e}_{1}+K_{11} \dot{e}_{1}+K_{12} e_{1}=0$

$\ddot{e}_{2}+K_{21} \ddot{e}_{2}+K_{22} \dot{e}_{2}+K_{23} e_{2}=0$

The gain parameters $K_{11}, K_{12}, K_{21}, K_{22}$, and $K_{23}$ are determined by assigning desired poles on the left-half $S$ plane and, thus, asymptotic tracking control to the reference can be achieved. From $u_{1}$ and $u_{2}$, the control signals in $d^{\prime}-q^{\prime}$ frame are determined by,

$V_{\mathrm{p} d^{\prime}}=-u_{1} \quad$ and $\quad V_{\mathrm{p} q^{\prime}}=-u_{2}$

Again, from $V_{\mathrm{p} d^{\prime}}, V_{\mathrm{p} q^{\prime}}$, the control signals in $d-q$ frame, i.e. $V_{\mathrm{p} d}$ and $V_{\mathrm{p} q}$, are obtained by making use of Eqs. (15) and (16).

\section{Simulation results}

The performance of the nonlinear feedback linearizing controller is evaluated and compared with that of cascade PI control structure by computer simulation. In the simulations, four different types of load models have been used. They are: linear impedance load, nonlinear impedance load, rectifier load and induction motor load. The mathematical models of the loads and their parameters are included in Appendix A. The parameters 
of the feedback linearizing controller and the conventional cascade PI controllers are listed in Appendix A.

Fig. 5 shows the simulation performances for linear impedance load when the values of $G$ and $B$ both increase by $50 \%$ from their nominal value after $0.1 \mathrm{~s}$. Clearly, the feedback linearizing (FL) controller has superior stabilizing performance over the conventional cascade PI control architecture.

The transient performance for ac-bus voltage $\left(V_{\mathrm{t}}\right)$ and dc-bus voltage $\left(V_{\mathrm{dc}}\right)$ are compared in Fig. 6 for nonlinear impedance load. In this case also, the FL controller outperforms cascade PI controller both in terms of overshoot and settling time. Some more results for nonlinear impedance load are displayed in Figs. 7 and 8 .

Figs. 9 and 10 display the simulation results for a rectifier load for change in load resistance and firing angle, respectively. Again, the superior performance of the FL controller is demonstrated for both types of disturbances.

The simulation studies are carried out for induction motor load for various types of disturbances, i.e. increase in load torque, decrease in load torque, change
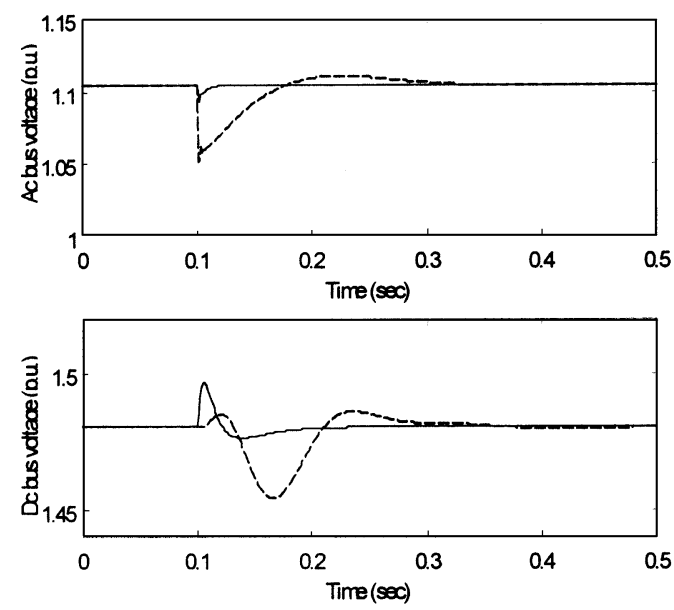

in transmission line impedance by line switching in a double circuit transmission line between the STATCOM ac-bus and power system receiving end bus, power system frequency change. The simulation performance for these disturbances are shown in Figs. 11-14, respectively. Here, also, the FL controller has superior performance over that of PI controller even in the presence of parameter changes (change in system frequency and line impedance). Finally, as an additional illustration, Fig. 15 shows the comparison of controller performances for a step $(5 \%)$ change in $V_{\mathrm{dc}}^{\text {ref }}$.

From the above computer simulation results, it is demonstrated that the feedback linearizing controller always has superior stabilizing properties over the cascade PI controller architecture. This is mainly attributed to nonlinear nature of the FL controller. As to choice of controller parameters, it is extremely difficult to choose a set of PI gains for some desired performance. In comparison, the pole placement in FL controller becomes a far simpler task and this makes it attractive.

Remark: in the computation of control outputs, it is to be ensured that $\mathbf{E}(\mathbf{x})$ is invertible at each step. It can
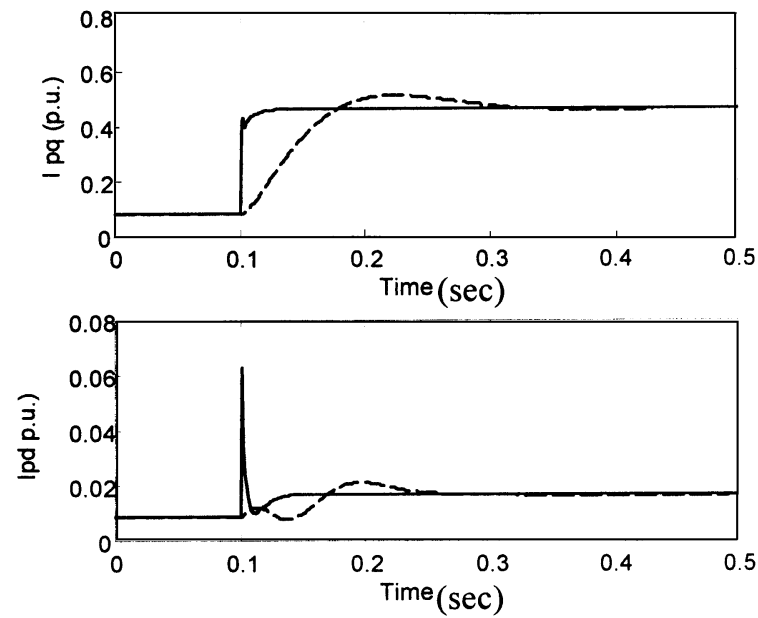
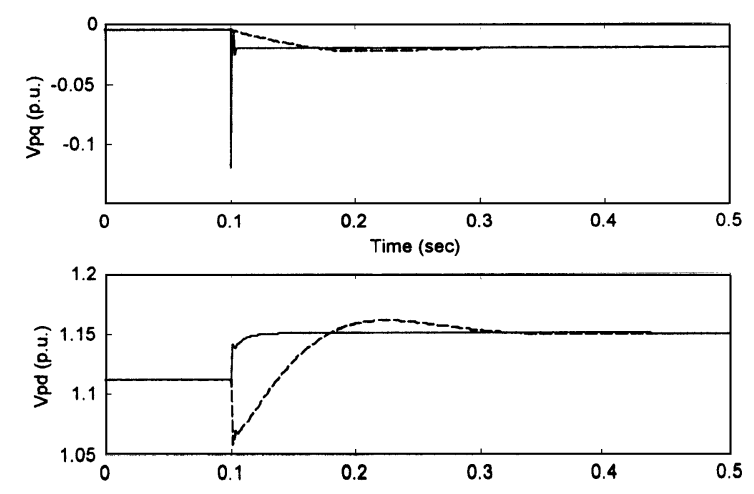

Fig. 5. Comparison of transient performances for $50 \%$ change in linear impedance bad; $G_{0}=0.8, B_{0}=0.4$, FL (-), PI (- - -). 

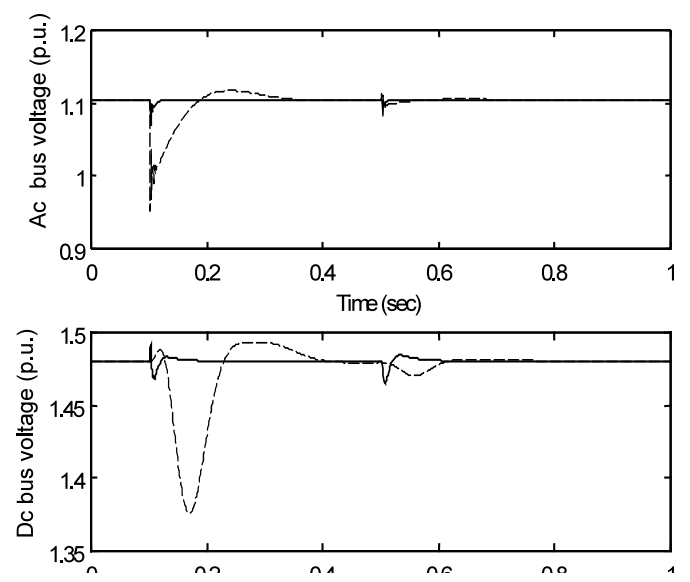

Fig. 6. Comparison of transient responses for nonlinear impedance bad, FL (-), PI (- - ); initially $P_{0}=0.8, Q_{0}=0.4, n_{1}=3$, and $n_{2}=1.5$; after $0.1 \mathrm{~s}, P=2.5 P_{0}$ and $Q=2.5 Q_{0}, n_{1}=3$, and $n_{2}=1.5$; after $0.5 \mathrm{~s}, n_{1}=2$, and $n_{2}=3, P=2.5 P_{0}$ and $Q=2.5 Q_{0}$.

be readily observed that it is very difficult to prove the definite invertibility of $\mathbf{E}(\mathbf{x})$, in general, over wide operating ranges and loading conditions, since the matrix elements depend on the state vector. In all the simulation studies carried out in this work, the control algorithm does not suffer from this problem. However, for safety, provisions have been made to switch to conventional PI control structure when $\mathbf{E}(\mathbf{x})$ is not invertible. Another alternative approach may be employed under such situations, i.e. the control outputs may be taken to be the same as those obtained in the previous step.
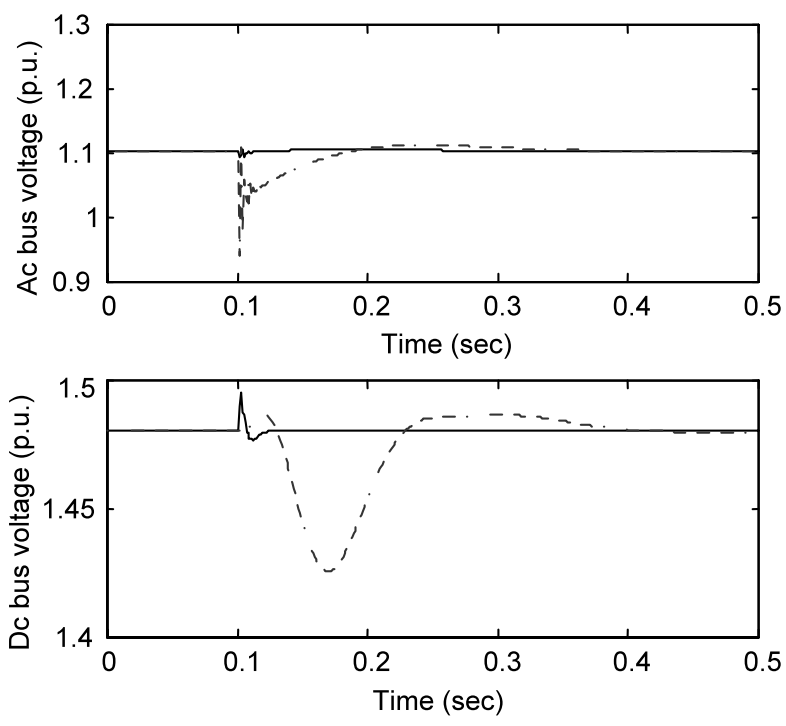

Fig. 7. Comparison of transient responses for nonlinear load, FL (-), PI (- - -); initially $P_{0}=0.8, Q_{0}=0.4, n_{1}=3$, and $n_{2}=1.5$; after $0.1 \mathrm{~s}$, $P=3 P_{0}$ and $Q=2 Q_{0}, n_{1}=3$, and $n_{2}=1.5$.
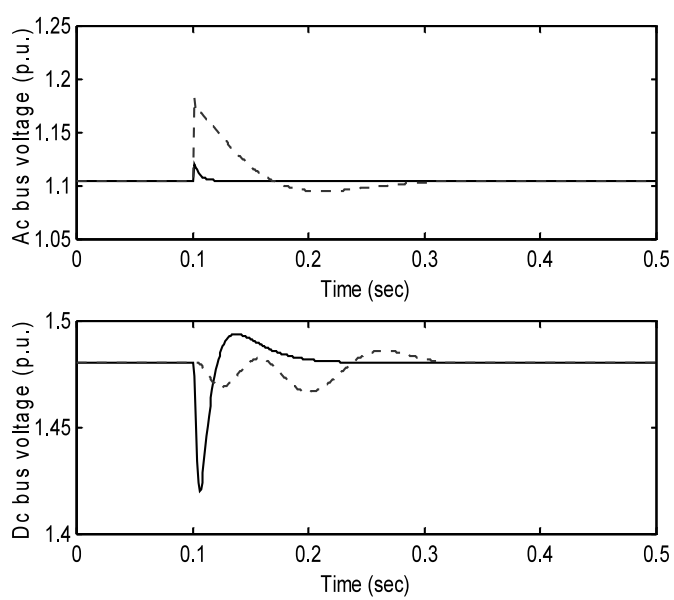

Fig. 8. Comparison of transient responses for nonlinear load, FL (-), PI (- - ) ; initially $P_{0}=0.8, Q_{0}=0.4, n_{1}=3$, and $n_{2}=1.5$; after $0.1 \mathrm{~s}$, $P=0.1 P_{0}$ and $Q=0.5 Q_{0}, n_{1}=3$, and $n_{2}=1.5$.

\section{Conclusions}

A nonlinear control approach based on linearization has been proposed, in this work, for high performance control of STATCOM in a power system distribution network. The novelty of the design approach is that the nonlinearity appearing in the system model is eliminated by input-output linearization, thereby, facilitating the use of a linear control law obtained via pole placement. As illustrated by computer simulation results, the superior transient performance of the proposed control strategy over the conventional cascade control approach has been established for various types of disturbances with both static and dynamic loads.

For the present design, the poles are placed at fixed locations throughout the system operation. A better and elegant approach will be to go for adaptive pole placement which is currently under investigation by the authors. Further, since the basic approach of feedback linearization technique is very much similar to
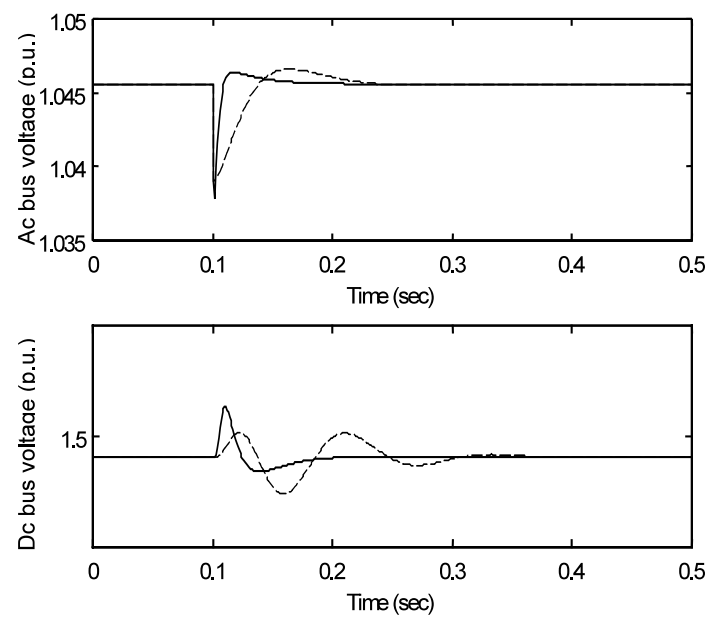

Fig. 9. Transient responses for rectifier load with a change in load resistance (from 7 to 3.5 at $0.1 \mathrm{~s}$ ) and $\alpha=10^{\circ}, \mathrm{FL}(-)$, PI (- - $)$. 

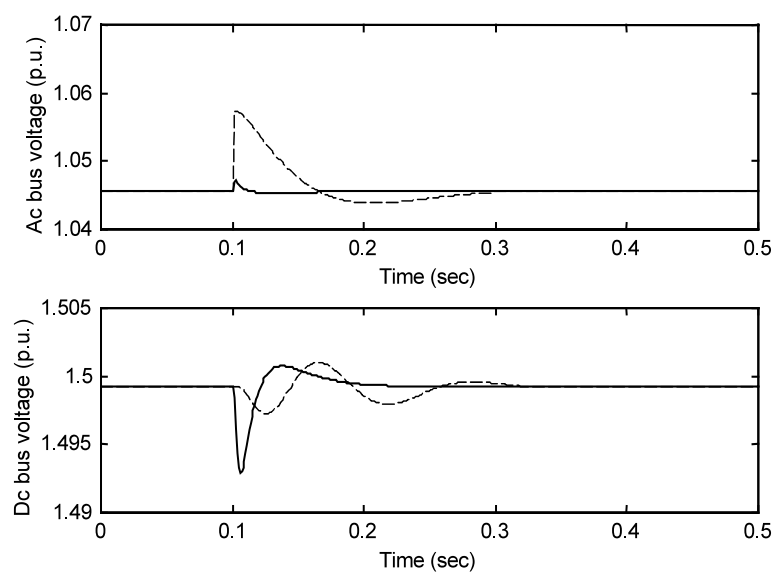

Fig. 10. Transient performance for change in firing angle (from 10 to $30^{\circ}$ at $\left.0.1 \mathrm{~s}\right)$ and load resistance $=7$ for a rectifier load, FL $(-)$, PI $(---)$.

inverse system method and techniques based on ANNbased inverse model identification and control, these control tools should be investigated thoroughly for STATCOM control and the authors are presently investigating this.

\section{Appendix A}

System data

$\omega_{0}=2 \pi f_{0}, f_{0}=50 \mathrm{~Hz}, R_{\mathrm{e}}=0.05$.

$\omega_{0} L_{\mathrm{e}}\left(=X_{\mathrm{e}}\right)=0.15, R_{\mathrm{p}}=0.04, \omega_{0} L_{\mathrm{p}}\left(=X_{\mathrm{p}}\right)=0.1$.

$R_{\mathrm{dc}}=150, C=5000 \mu \mathrm{F}$.

Linear impedance load

$Y=G-j B$

Voltage at the load bus $=V_{\mathrm{r} d}+j V_{\mathrm{r} q}$

Load current $=\left(G V_{\mathrm{r} d}+B V_{\mathrm{r} q}\right)+j\left(G V_{\mathrm{r} q}-B V_{\mathrm{r} d}\right)$
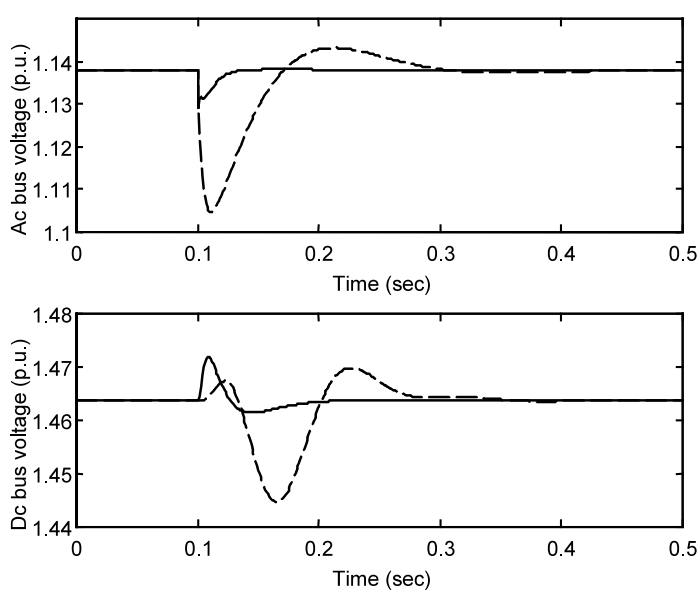

Fig. 11. Transient responses for change in load torque (increases by $50 \%$ after $0.1 \mathrm{~s})$, FL (-), PI (- - -).
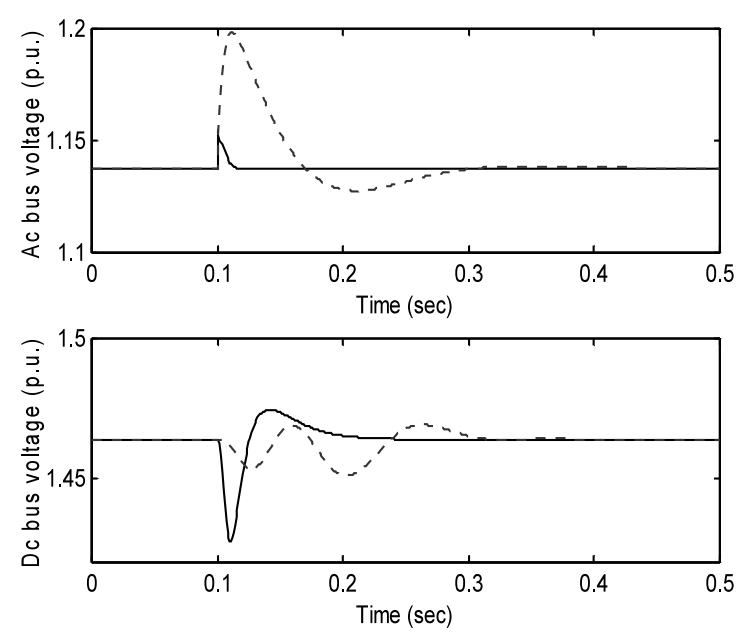

Fig. 12. Transient responses for change in load torque (decreases by $80 \%$ after $0.1 \mathrm{~s})$, FL (-), PI (- - -).

\section{Nonlinear impedance load}

$P_{\mathrm{L}}=P_{\mathrm{L} 0}\left(\frac{V_{\mathrm{r}}}{V_{\mathrm{r} 0}}\right)^{n_{1}} \quad Q_{\mathrm{L}}=Q_{\mathrm{L} 0}\left(\frac{V_{\mathrm{r}}}{V_{\mathrm{r} 0}}\right)^{n_{2}}$

where $n_{1}$ and $n_{2}$ are the indices $(>0)$.

\section{Rectifier load}

The diagram below shows the structure of rectifier load.
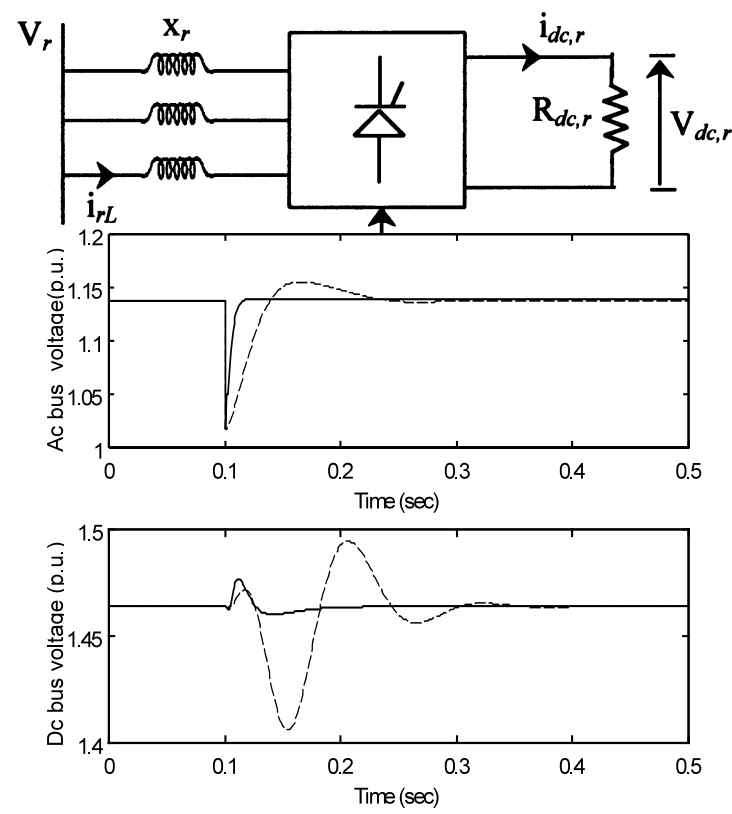

Fig. 13. Transient performances for line switching after $0.1 \mathrm{~s}, \mathrm{FL}(-)$, PI $(---)$. 

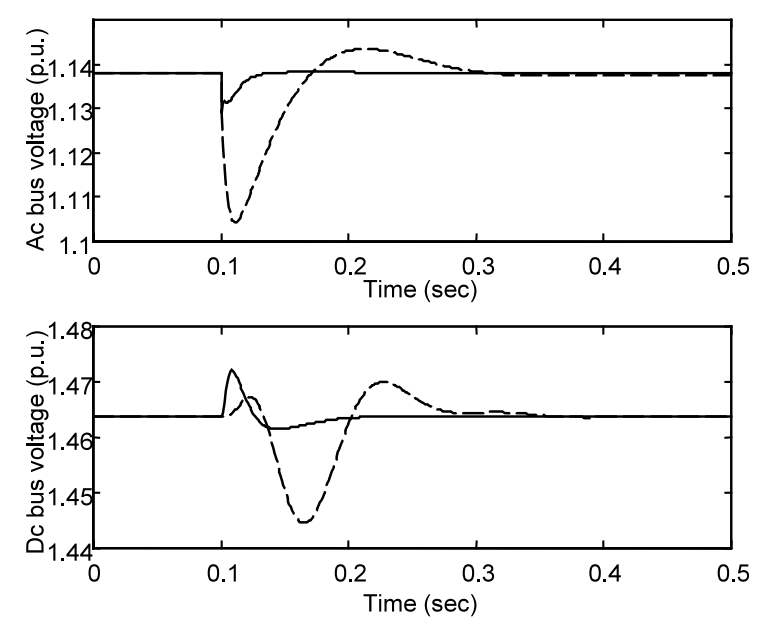

Fig. 14. Transient performances in case of power system frequency change (by $2 \mathrm{~Hz}$ ) after $0.1 \mathrm{~s}$, FL (-), PI (- - ).

$$
\begin{aligned}
& V_{\mathrm{dc}, \mathrm{r}}=\frac{3 \sqrt{2}}{\pi} V_{\mathrm{r}, \mathrm{LL}} \cos \alpha-\frac{3 x_{\mathrm{r}} i_{\mathrm{dc}, \mathrm{r}}}{\pi} \\
& i_{\mathrm{rL}}=\frac{\sqrt{6}}{\pi} i_{\mathrm{dc}, \mathrm{r}}
\end{aligned}
$$

$\cos \delta=\cos \alpha-\frac{i_{\mathrm{dc}, \mathrm{r}} x_{\mathrm{r}}}{\sqrt{2} V_{\mathrm{r}, \mathrm{LL}}}$

where $\alpha$ is the firing angle and $\delta$ is the phase difference between ac-side voltage and current.

$$
P_{\mathrm{dc}, \mathrm{r}}=0.8, R_{\mathrm{dc}, \mathrm{r}}=7, \alpha=10^{\circ}, x_{\mathrm{r}}=0.1 \text {. }
$$

\section{Induction motor load [21]}

A third order induction motor model is taken as given below.
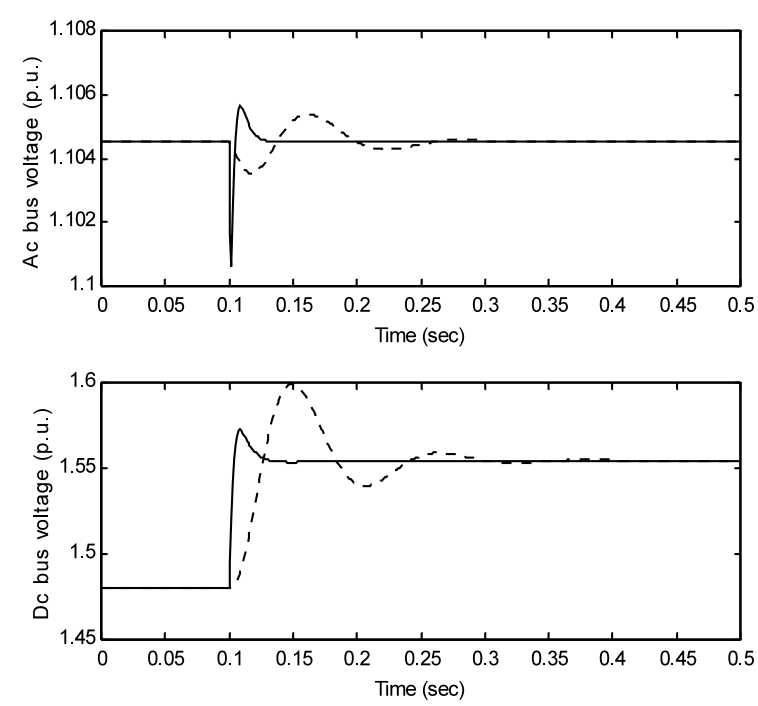

Fig. 15. Comparison of performances for a step ( $5 \%$ change in de bus reference voltage, FL $(-)$, PI (- - -).

\section{Stator}

$V_{d \mathrm{~s}}=E_{d}^{\prime}-X^{\prime} I_{q \mathrm{~s}}$

$V_{q \mathrm{~s}}=E_{q}^{\prime}-X^{\prime} I_{d \mathrm{~s}}$

Rotor

$T_{0}^{\prime} \frac{\mathrm{d} E_{q}^{\prime}}{\mathrm{d} t}=-E_{q}^{\prime}+\frac{X_{\mathrm{m}}^{2}}{X_{\mathrm{r}}} I_{d \mathrm{~s}}-s \frac{X_{\mathrm{r}}}{R_{\mathrm{r}}} E_{d}^{\prime}$

$T_{0}^{\prime} \frac{\mathrm{d} E_{d}^{\prime}}{\mathrm{d} t}=-E_{d}^{\prime}+\frac{X_{\mathrm{m}}^{2}}{X_{\mathrm{r}}} I_{q \mathrm{~s}}-s \frac{X_{\mathrm{r}}}{R_{\mathrm{r}}} E_{q}^{\prime}$

Torque equation

$2 H \frac{\mathrm{d} s}{\mathrm{~d} t}=T_{\mathrm{L}}-\left(E_{q}^{\prime} I_{q \mathrm{~s}}+E_{d}^{\prime} I_{d \mathrm{~s}}\right)$

The mechanical load torque is assumed to be proportional to rotor speed. Thus,

$T_{\mathrm{L}}=k_{0} \omega_{\mathrm{r}}=k_{0} \omega_{\mathrm{s}}(1-s)=k_{\mathrm{L}}(1-s)$
$X^{\prime}=\frac{X_{\mathrm{s}} X_{\mathrm{r}}-X_{\mathrm{m}}^{2}}{X_{\mathrm{r}}}, \quad T_{0}^{\prime}=\frac{X_{\mathrm{r}}}{\omega_{\mathrm{s}} R_{\mathrm{r}}}, \quad s=\frac{\omega_{\mathrm{s}}-\omega_{\mathrm{r}}}{\omega_{\mathrm{s}}}$

$X_{\mathrm{s}}=1.2287, \quad X_{\mathrm{r}}=1.2233, \quad X_{\mathrm{m}}=1.18, \quad R_{\mathrm{r}}=0.0053$, $\omega_{\mathrm{s}}=2 \pi f_{0}, H=0.41, R_{\mathrm{s}}=0.0079, V_{d \mathrm{~s}}$ and $V_{q \mathrm{~s}}$ correspond to voltages of the load bus.

\section{Controller data}

Cascade PI controller

The parameters of the PI controller are determined by a thorough and repeated study of the system responses under various operating conditions. The PI controller settings, which give the best responses under all the tested conditions are listed below.

$K_{\mathrm{pt}}=1.0, K_{\mathrm{it}}=333.33, K_{\mathrm{p} q}=5, K_{i q}=1667$

$K_{\mathrm{pc}}=0.1, K_{\mathrm{ic}}=10, K_{\mathrm{p} d}=50, K_{\mathrm{id}}=16667$

\section{Feedback linearizing controller}

Desired pole locations for computation of $K_{11}$ and $K_{12}$ are: $s_{1}=-100, s_{2}=-10$ and for computation of $K_{21}, K_{22}$ and $K_{23}$ are: $s_{1}=-200, s_{2}=-100, s_{3}=-50$.

\section{References}

[1] L. Gyugyi, Dynamic compensation of AC transmission lines by solid-state synchronous voltage sources, IEEE Transactions on Power Delivery 9 (3) (1994) 345.

[2] B.N. Singh, A. Chandra, K. Al-Haddad, DSP-based indirectcurrent-controlled STATCOM, Part 2: multifunctional capabilities, IEE Proceedings on Electric Power Application 147 (2) (2000) $113-118$.

[3] B.M. Han, G.G. Karady, J.K. Park, S.I. Moon, Interaction analysis model for transmission static compensator with EMTP, IEEE Transactions on Power Delivery 13 (4) (1998) 1297-1302.

[4] H.F. Hang, F. Li, Multivariable sampled regulators for the coordinated control of STATCOM AC and DC voltage, IEE 
Proceedings on Generation, Transmission and Distribution 147 (2) (2000) 93-98.

[5] S. Mori, K. Matsuno, M. Takeda, M. Seto, Development of a large static var generator using self-commutated inverters for improving power systems stability, IEEE Transactions on Power Systems 8 (1) (1993) 371-378.

[6] M. Mohaddes, A.M. Gole, P.G. McLaren, A neural network controlled optimal pulse-width modulated STATCOM, IEEE Transactions on Power Delivery 14 (2) (1999) 481-488.

[7] K.R. Padiyar, A.M. Kulkarni, Control design and simulation of a unified power flow controller, IEEE Transactions on Power Delivery 13 (4) (1998) 1348-1354.

[8] C. Schauder, H. Mehta, Vector analysis and control of advanced static VAR compensators, IEE proceedings - C 140 (4) (1993) 299-306.

[9] P.W. Lehn, M.R. Iravani, Experimental evaluations of STATCOM closed loop dynamics, IEEE Transactions on Power Delivery 13 (4) (1998) 1378-1384.

[10] J.E. Slotine, W. Li, Applied Nonlinear Control, Prentice-Hall International Editions, USA, 1991, pp. 207-271.

[11] W. Mielczarski, A.M. Zajaczkowski, Nonlinear field voltage control of a synchronous generator using feedback linearization, Automatica 30 (10) (1994) 1625-1630.

[12] H. Sira-Ramirez, M. Ilic-Spong, Exact linearization in switchedmode DC-to-DC power converters, International Journal of Control 50 (2) (1989) 511-524.
[13] D.I. Kim, I.J. Ha, M.S. Ko, Control of induction motor via feedback linearization with input-output decoupling, International Journal of Control 51 (4) (1990) 863-886.

[14] Y.L. Tan, Y. Wang, Design of series and shunt FACTS controller using adaptive nonlinear coordinated design techniques, IEEE Transactions on Power Systems 12 (3) (1997) 1374-1379.

[15] Y.L. Tan, Y. Wang, Augmentation of transient stability using a superconducting coil and adaptive nonlinear control, IEEE Transactions on Power Systems 13 (2) (1998) 361-366.

[16] Z. Xu, L.R. Hunt, On the largest input-output linearizable subsystem, IEEE Transactions on Automatic control 41 (1) (1996) $128-132$.

[17] K.S. Narendra, S. Mukhopadhyay, Adaptive control of nonlinear multivariable systems using neural networks, Neural Networks 7 (5) (1994) 737-753.

[18] Peter Idowu, Robust neural net based inverse model identification of an induction motor, Electric machines and Power systems 27 (5) (1999) 513-525.

[19] G. Lightbody, G.W. Irwin, Nonlinear control structures based on embedded neural systems models, IEEE Transactions on Neural Networks 8 (3) (1997) 553-567.

[20] P. Vas, Vector control of AC Machines, Oxford university press, New York, 1990.

[21] B.C. Lesieutre, P.W. Sauer, M.A. Pai, Development and comparative study of induction machine based dynamic P,Q load models, IEEE Transactions on Power Systems 10 (1) (1995) 182 191. 